Psychopharmacology (Berl). 2016 September ; 233(17): 3077-3087. doi:10.1007/s00213-016-4344-4.

\title{
Abnormal fronto-limbic engagement in incarcerated stimulant users during moral processing
}

\author{
Samantha J. Fede ${ }^{1,2}$, Carla L. Harenski ${ }^{2}$, Jana Schaich Borg ${ }^{3}$, Walter Sinnott-Armstrong ${ }^{3}$, \\ Vikram Rao ${ }^{2}$, Brendan Caldwell ${ }^{2}$, Prashanth K. Nyalakanti ${ }^{2}$, Mike Koenigs ${ }^{4}$, Jean Decety ${ }^{5}$, \\ Vince C. Calhoun ${ }^{1,2}$, and Kent A. Kiehl ${ }^{1,2}$ \\ ${ }^{1}$ University of New Mexico, Albuquerque, NM \\ ${ }^{2}$ Mind Research Network, Albuquerque, NM \\ ${ }^{3}$ Duke University, Durham, NC \\ ${ }^{4}$ University of Wisconsin, Madison, WI \\ 5 University of Chicago, Chicago, IL
}

\begin{abstract}
Rationale-Stimulant use is a significant and prevalent problem, particularly in criminal populations. Previous studies found that cocaine and methamphetamine use is related to impairment in identifying emotions and empathy. Stimulant users also have abnormal neural structure and function of the ventromedial prefrontal cortex (vmPFC), amygdala, anterior (ACC) and posterior cingulate (PCC), regions implicated in moral decision making. However, no research has studied the neural correlates of stimulant use and explicit moral processing in an incarcerated population.
\end{abstract}

Objectives-Here we examine how stimulant use affects sociomoral processing that might contribute to antisocial behavior. We predicted that vmPFC, amygdala, PCC, and ACC would show abnormal neural response during a moral processing task in incarcerated methamphetamine and cocaine users.

Methods-Incarcerated adult males $(N=211)$ were scanned with a Mobile MRI system while completing a moral decision making task. Lifetime drug use was assessed. Neural responses during moral processing were compared between users and non-users. The relationship between duration of use and neural function was also examined.

Results-Incarcerated stimulant users showed less amygdala engagement than non-users during moral processing. Duration of stimulant use was negatively associated with activity in ACC and positively associated with vmPFC response during moral processing.

Conclusions-These results suggest a dynamic pattern of fronto-limbic moral processing related to stimulant use with deficits in both central motive and cognitive integration elements of

Corresponding Author: Samantha J. Fede, Mind Research Network, 1101 Yale Blvd NE, Albuquerque, NM, 87106, sjfede@ unm.edu, 505-301-4134.

The authors do not have any financial conflicts of interest. 
biological moral processes theory. This increases our understanding of how drug use relates to moral processing in the brain in an ultra-high risk population.

\section{Keywords}

Morality; fMRI; cocaine; methamphetamine; stimulant; vmPFC; ACC; limbic

Substance abuse is a staggering problem, costing the United States up to $\$ 11$ billion dollars in annual health care costs alone. When considering other factors, such as crime and lost productivity, the cost is more than ten times that (NIDA 2014). In addition to the societal costs, users of stimulants, such as cocaine and methamphetamine, have significant lifetime prevalence rates, with over $15 \%$ of all adults in the United States having used cocaine and upwards of 5\% having used methamphetamine (SAMSHA 2011). Additionally, 1.5 million people in the United States are current cocaine users while nearly 600,000 are current methamphetamine users, nearly tripling the number of current users since 2011 (SAMSHA 2014). Meanwhile, nearly $50 \%$ of prison inmates report having used cocaine or methamphetamine in their lifetimes. Additionally, $12 \%$ report being high on cocaine while committing their crime while an additional $6 \%$ of inmates report using methamphetamine at the time of offense (BJS 2004).

As might be expected given the relation between stimulant use and crime, research has suggested that stimulant abusers show deficits in several types of socio-affective processes that are related to moral judgement and prosocial behavior. Both active and abstinent stimulant users have difficulty identifying others' emotions, particularly fear (Fox et al. 2007; Fox et al. 2011; Kemmis et al. 2007; Morgan and Marshall 2013). Additionally, stimulant use is related to diminished empathy and perspective taking (Ferrari et al. 2014; Henry et al. 2009; Kim et al. 2011a; Kim et al. 2010; Preller et al. 2014), abilities that play an important role in moral decision making (Bzdok et al. 2012).

In addition to behavioral deficits, chronic stimulant users exhibit abnormal neural engagement in both top down and bottom up processes, such as significantly reduced activation compared to controls in the anterior cingulate (ACC), prefrontal cortex, and posterior cingulate (PCC) during response inhibition, prediction, and stress imagery (Aron and Paulus 2007). Abusers of both illicit and non-illicit stimulants also show increased ACC activity during reward cues (Garavan et al. 2000) and less amygdala and prefrontal cortex activations during delay discounting (Hoffman et al. 2008), although another study of intertemporal choice found less activation in methamphetamine users compared to controls in the dorsal ACC (Monterosso et al. 2007). This pattern of both hypo- and hyper-activations in various brain regions is thought to reflect neurocognitive impairments and compensatory cognitive processes, respectively (Crunelle et al. 2012).

Anatomical imaging studies have found that chronic stimulant use is associated with reduced gray matter in the ventromedial prefrontal cortex (vmPFC), insula, and temporal cortex (Mackey and Paulus 2013). Reductions have also been detected in other frontal regions including anterior and posterior cingulate as well as the amygdala (Alia-Klein et al. 2011; Bartzokis et al. 2000; Daumann et al. 2011; Ersche et al. 2011; Ersche et al. 2012; Franklin et al. 2002; Makris et al. 2004; Matochik et al. 2003; Morales et al. 2012; Moreno-Lopez et 
al. 2012; Nakama et al. 2011; Rando et al. 2013; Sim et al. 2007; Thompson et al. 2004). These patterns of structural abnormalities combine with functional work to suggest a pattern of frontocorticol deficits in chronic methamphetamine users (London et al. 2015).

Several of the regions implicated in functional and anatomical imaging studies of stimulant use, particularly the vmPFC, amygdala, PCC, and ACC, are consistently engaged during moral judgments in non-clinical populations. During moral processing in the brain, event sequences are stored in the prefrontal cortex and then represented in the vmPFC.

Meanwhile, emotional experiences are represented in limbic regions such as the amygdala and PCC (Moll et al. 2005). The connections between these regions enable moral decisions, with the ACC playing an important role coordinating reinforcement, affect, and executive action (Shackman et al. 2011). Additionally, the PCC is engaged during evaluative behavior such as theory of mind, self-reflection, and emotion integration during moral decisionmaking (Fletcher et al. 1995; Johnson et al. 2006; Vogt et al. 1992). Thus, poor decision making, including antisocial behavior, in stimulant users may be related to abnormalities in the neural network responsible for evaluating and making decisions about moral situations. Work with methamphetamine users has found evidence of functional connectivity deficits between frontal and corticolimbic regions leading to risky decision making (Kohno et al. 2014) and impulsivity (Kohno et al. 2016).

Only two studies to date have directly examined how stimulant users' brains process morally-salient stimuli (Caldwell et al. 2015; Verdejo-Garcia et al. 2014). In one study, cocaine users who were participating in an inpatient treatment program, relative to noncocaine users, showed lower task related activity in the dorsal ACC while evaluating moral dilemmas (Verdejo-Garcia et al. 2014). Additionally, in previous work we found that abstinent, incarcerated cocaine-users, relative to non-using incarcerated controls, had lower activation in the ACC and vmPFC during implicit moral processing (Caldwell et al. 2015). Implicit moral processing triggers automatic moral processes but does not have moral task demands (e.g., shows a picture of a murder scene and asks if the scene is inside or outside.) However, to our knowledge, no study to date has investigated the neural correlates of explicit (i.e., having moral task demands) moral judgment in incarcerated methamphetamine abusers, despite the fact that many addicts become incarcerated at some point in their lives and $75 \%$ of inmates have substance abuse problems, according to epidemiological studies (Peters et al. 1998).

Here we examined moral processing in cocaine and methamphetamine chronic users in a large incarcerated sample, allowing us to assess the effects of chronic stimulant use not confounded by acute use and compared to a control group matched on incarceration and background. We hypothesized that incarcerated individuals with a history of chronic stimulant use, compared to incarcerated individuals with no history of regular stimulant use, would show reduced activation in the ACC, PCC, amygdala, and vmPFC when making moral judgments about morally controversial issues. These regions have been found to be significantly engaged in non-incarcerated, non-substance abusing individuals during moral processing (Schaich Borg et al. 2011) and are related to abnormal grey matter volume and function in chronic substance users (see discussion above).. We also predicted that duration 
of stimulant use, quantified by years of regular cocaine and methamphetamine use, would be related to more pronounced abnormalities in these regions.

\section{Methods}

\section{Participants}

Participants were adult males incarcerated in New Mexico and Wisconsin prisons ( $N=211)$. Inclusion criteria were: age between 18 and 65, IQ of 80 or above, at least $4^{\text {th }}$ grade English reading level, and no history of neurological disorder or history of psychosis in self or firstdegree relative. Participants with a history of regular stimulant use $(n=131)$ were compared to participants with no history of regular stimulant use $(n=80)$. Characteristics of each group are provided in Table 1.

All participants provided written, informed consent prior to their inclusion in the study and were compensated at an hourly rate comparable to pay rates for work within the facilities. All procedures and materials were approved by the University of New Mexico Institutional Review Board (IRB) and thus have been performed in accordance with the ethical standards of the Declaration of Helsinki.

\section{Assessments}

Substance use was assessed using a modified version of the Addiction Severity Index (ASIX) (McLellan et al. 1992), in which participants were asked about characteristics of use for a variety of substance classes, including age of first use and years of regular use (defined as three or more times a week). If a participant had any regular use of cocaine or methamphetamine in his lifetime, he was classified as a lifetime stimulant user. This was also used to quantify lifetime years of regular non-stimulant drug and alcohol use. Although methamphetamine and cocaine are distinct substances, both are stimulant class and there is precedent for examining their use together [i.e., (Brodie et al. 2005; Clark et al. 2014; Dixon and Bejar 1989)], as well as evidence that the substances have similar trajectories (Hser et al. 2008), effects on the brain (van der Plas et al. 2009) and outcomes (Rawson et al. 2000).

In addition to the ASI-X, we collected additional measures to quantify possible confounding factors as well as to evaluate for the exclusion criteria discussed above. Smoking was assessed using the Fagerstrom Test for Nicotine Dependence (Heatherton et al. 1991). IQ was estimated using the Vocabulary and Matrix Reasoning subtests of the Adult Intelligence Scale (WAIS) (Ryan et al. 1999; Wechsler 1997). Because stimulant use is likely to be comorbid with psychopathy (Hemphill et al. 1994; Walsh et al. 2007), psychopathy and stimulant abuse show overlapping brain regions of decreased structure/function (Crunelle et al. 2012; Kiehl et al. 2006), and psychopathy is higher among incarcerated versus nonincarcerated individuals (BJS 2004; NIDA 2014), psychopathy was assessed in all study participants using the Hare Psychopathy Checklist- Revised (PCL-R) (Hare 2003). The PCL-R is the most widely used assessment of psychopathy in forensic populations, consisting of a semi-structured interview on topics such as interpersonal style and criminal history. Participants are scored on a scale of 0-40, where higher scores indicate stronger psychopathic traits. Psychiatric histories were assessed with the Structured Clinical 
Interview for DSM-IV disorders (SCID)(First et al. 1997) both to evaluate psychotic disorders for exclusion purposes and to evaluate other Axis I disorders. All interviews were conducted by trained research staff.

\section{Moral task}

Participants were shown words and phrases describing moral acts or concepts adapted from a task previously developed and validated by Schaich Borg and colleagues (2011). Fifty stimuli were classified as noncontroversial negative (e.g., murder, slavery), fifty were classified as noncontroversial positive (e.g., charity, kindness), and fifty were classified as controversial (e.g., animal testing, gun control). Controversial stimuli required more processing than noncontroversial stimuli; this was confirmed in our study by an increased response time to the stimuli. Participants were presented with a given stimulus and asked to press one button to indicate they thought the word or phrase was morally wrong and a different button to indicate that they thought the stimuli was morally not wrong. After the button was pressed, a black screen was shown jittered for 1 to 6 seconds. Three runs of the task were administered, each including 50 stimuli evenly divided amongst stimulus types.

\section{MRI data acquisition}

Participants were scanned using the Mind Research Network's 1.5T Siemens Avanto mobile MRI scanner stationed at correctional facilities. The scans were acquired using an EPI gradient-echo pulse sequence (parameters: repetition time (TR) 2000, echo time (TE) $39 \mathrm{ms,}$ flip angle $75^{\circ}$, FOV $24 \times 24 \mathrm{~cm}, 64 \times 64$ matrix, $4 \mathrm{~mm}$ slice thickness with a $1 \mathrm{~mm}$ gap, 27 slices). The task was presented using E-Prime software (Psychological Software Tools 2012). A T1-weighted scan was collected (parameters: TR 2530, TE $1.64 \mathrm{~ms}, 3.50 \mathrm{~ms}$, $5.36 \mathrm{~ms}, 7.22 \mathrm{~ms}$, inversion time $=1100 \mathrm{~ms}$, flip angle $7^{\circ}$, slice thickness $=1.3 \mathrm{~mm}, 256 \times 256$ matrix), but it was not used in any of the functional MRI post-processing.

\section{Image preprocessing and analyses}

Imaging data were preprocessed with Statistical Parametric Mapping software (SPM). Head motion was corrected using the ArtRepair Toolbox in SPM to identify and remove severe artifacts (Mazaika et al. 2009), defined as time points with signal change greater than $4 \%$ of the global mean signal, then INRIAlign to estimate head motion using an algorithm that is insensitive to eye movements and blood oxygenation level dependent (BOLD) activity (Freire et al. 2002). We then spatially normalized images to the Montreal Neurological Institute (MNI) template and smoothed with an $8 \mathrm{~mm}$ full-width at half-maximum Gaussian smoothing kernel. A high-pass filter removed low-frequency drift below 1/128 Hertz.

We modeled two conditions of interest at the single-subject level using the general linear model (GLM). These conditions were controversial and noncontroversial (including both positive and negative stimuli). We examined the conditions time-locked to participant response. At the group-level, the conditions of interest were compared using a one-sample $t$ test (controversial > noncontroversial). The main effects of this analysis replicated previous use of this task in healthy controls (Schaich Borg et al. 2011). 
We then used a two sample $t$-test to compare BOLD responses for this contrast between the lifetime stimulant use group and non-stimulant use group. Additionally, we examined the impact of stimulant use duration on moral processing by regressing total years of regular stimulant use in a separate statistical analysis using only participants in the lifetime stimulant use group. This stimulant use duration measure may in part quantify stimulant use severity.

We did not use years of non-stimulant substance and alcohol use as a covariate in our primary group comparisons because it was significantly different between groups; this means that including it as a covariate would remove variance from the group difference, not the error variance (Miller and Chapman 2001). In order to control for confounding variables in the regression model only, we used years of non-stimulant substance and alcohol use as a covariate in the regression of hemodynamic response by stimulant use duration; we also added age ( significantly related to duration of stimulant use: $r=.272, p=.002$, two-tailed Pearson, and PCL-R Total score to the model, but did not see substantive differences in the results.

To test our hypotheses, a priori brain regions of interest (ROIs) were examined including the ACC, PCC, amygdala, and vmPFC. Anatomical masks of these regions were generated from Wake Forest University Pick Atlas in SPM (Maldjian et al. 2004; Maldjian et al. 2003). A small-volume correction (SVC) was applied to determine the corrected $p$-values based on the size of each ROI using family wise error (FWE) rate correction for multiple comparisons. ROIs are represented in Figure 1. Additionally, a whole brain analysis corrected using FWE at $p<.05$ was conducted to examine areas outside our a priori regions of interest.

In order to understand the contribution of cocaine and methamphetamine use to the overall stimulant use effects, we ran additional analyses with the same contrast, covariates, and ROIs. The analyses were as follows: 1$)$ lifetime cocaine users $(n=118)$ versus non-cocaine users $(n=93)$; 2) lifetime methamphetamine users $(n=72)$ versus non-methamphetamine users $(n=139) ; 3)$ duration of lifetime cocaine use $(n=118)$; and 4$)$ duration of lifetime methamphetamine use $(n=72)$.

\section{Results}

\section{Lifetime Stimulant Users versus Non-Stimulant Users}

Stimulant users did not significantly differ from non-stimulant users on behavioral task performance, including response times and number of "wrong" vs. "not wrong" responses for any of the conditions of interest (i.e. controversial \& non-controversial stimuli; Table 2). These results did not change when years of non-stimulant and alcohol use was included as a covariate.

When making decisions about controversial moral phrases, lifetime stimulant users showed less hemodynamic activity in the right amygdala relative to non-stimulant users ( $x=30, y=$ $-3, z=-27, t=-3.13, k=51, p=.026 \mathrm{FWE}$ corrected). This same cluster was significant at a trend level in lifetime cocaine users compared to non-users $(k=49, t=-2.80, p=.055$ 
FWE corrected). No results in the whole brain analysis survived correction for multiple comparisons.

\section{Duration of Lifetime Stimulant Use}

Duration of lifetime stimulant use was not significantly associated with response times or number of "wrong" vs. "not wrong" responses in any of the conditions of interest (i.e., controversial \& non-controversial stimuli; Table 2). These results did not change when years of non-stimulant use was not included as a covariate.

In the regression, years of stimulant use was inversely related to hemodynamic response in the ACC ( $x=-15, y=21, z=27, k=29, t=-3.68, p=.042$ FWE corrected; Table 4). Years of cocaine use was also inversely related to engagement in that region, although at a trend level $(x=-15, y=18, z=27, k=24, t=-3.53, p=.061 \mathrm{FWE}$ corrected). Years of methamphetamine use were positively associated with hemodynamic response in the vmPFC ( $x=6, y=63, z=15, k=72, t=3.69, p=.049$ FWE corrected). No results in the whole brain analysis survived correction for multiple comparisons. These results did not change when years of non-stimulant use was included as a covariate. None of the results are presented as Figures? Was this always the case?

\section{Discussion}

Here we investigated how stimulant use affects hemodynamic activity related to moral processing in an ultra-high risk population. We found that duration of stimulant use was inversely related to caudal ACC activity, driven by cocaine use duration, while methamphetamine use duration was positively associated with vmPFC engagement. Additionally, regular stimulant users, relative to non-regular users, had hypoactivity in the right amygdala, driven by cocaine use in particular. These regions have essential roles in moral processing and emotional regulation.

The amygdala functions as a center for affective information during moral processing, interacting with goal oriented knowledge structures in the mPFC (Moll et al. 2005). Here we found abnormal responses within this system. An increase in vmPFC activity and decrease in amygdala activity is a typical pattern of hemodynamic response during emotional down regulation (Cunningham et al. 2004; Johnstone et al. 2007; Urry et al. 2006). This may reflect a specific deficit in the emotion regulation element of sociomoral processing; whereas non-stimulant users use a balance of emotional and cognitive resources to make moral decisions, stimulant users may be overly reliant on cognitive systems and downregulate emotional processes when arriving at a judgment.

An alternative explanation is that either the amygdala or the ACC alone has less engagement in stimulant users, but reciprocal connections between those regions account for the reduction in hemodynamic response in the other. Rather than a deficit in cognitive control, stimulant users may also find morally controversial issues less salient or may have poor emotional insight (Payer et al. 2011), eliciting a weaker amygdala response that requires less cognitive override. Connectivity studies have found that the amygdala and ACC are functionally connected during emotion regulation (Banks et al. 2007), fear (Williams et al. 
2006), and during resting state (Roy et al. 2009) as well as structurally connected by projections from the amygdala (Johansen-Berg et al. 2008; Kim et al. 2011)

Another possible explanation is increased reliance on the cognitive override process in the vmPFC, as posited by the cognitive control theory of moral processing (Greene et al. 2004). However, this is not consistent with our ACC findings. In this model, cognitive control processes sub served by the ACC override emotional responses to promote rational (e.g., utilitarian) moral judgments. The increased engagement in the vmPFC may still be related to cognitive control abnormality. The vmPFC, specifically of prefrontal regions, plays a key role in integrating emotions into decision making during moral judgment (Moll et al. 2005). Rather than requiring more cognitive override of emotions in moral decision making, the increase in activity in this region may indicate that stimulant users have increased difficulty in integrating emotions into those moral judgments and thus have increased activity in the vmPFC based on task demands. Our findings, as previously discussed, suggest less overall processing in both emotional response and cognitive override processes rather than an increase in cognitive processes.

The caudal ACC has been isolated as a region predictive of recidivism in criminal offenders, above and beyond general substance use (Aharoni et al. 2013). Specifically, individuals with lower activity in this region during response inhibition were twice as likely to reoffend. The current results may offer a potential mechanism for this pattern; if cognitive control during moral processing is deficient, it may incline an individual to commit moral violations often ending in rearrest.

The vmPFC and amygdala abnormalities have implications for the continued development of moral standards and behaviors in individuals with stimulant use disorders. The amygdala and vmPFC work together through stimulus reinforcement learning to associate distress with moral transgressions (Blair 2007). The vmPFC, a region involved in goal-oriented decisionmaking, has afferent connections to the amygdala, a region commonly implicated in fear conditioning (Barbas et al. 2003). When communications between the vmPFC and amygdala are abnormal during socioemotional processing, as has been found here and in a previous study (Payer et al. 2008), affected individuals are not socialized to avoid committing moral transgressions. Amygdala dysfunction is also particularly relevant for drug use as the amygdala is thought to play a role in drug addiction in terms of abnormal neurotransmitter production (Koob 1999).

Stimulant users often demonstrate deficiencies in cognitive control and corresponding neural hypoactivations; the vmPFC results do not necessarily provide evidence against this. Given that our chronic stimulant use participants display normal moral judgment in the task, task demands may have required that these individuals up-regulate their processes for integrating emotion into decision-making. Individuals with lesions to the vmPFC often have abnormal moral judgment and psychopathic behavior (Ciaramelli et al. 2007; Koenigs et al. 2007; Moretto et al. 2010; Thomas et al. 2011), since they cannot upregulate, as well as amygdala hyper reactivity to negative stimuli (Motzkin et al. 2015), possibly as a compensatory process on the other side of the amygdala-vmPFC system. It is important to note, however, that methamphetamine and cocaine appear to be contributing separately to abnormalities in 
these two connecting regions; although lesions to either region have been sufficient to impair moral processing (Bechara and Damasio 2005), this distinction may reflect compounding effects of poly-stimulant use.

These results are consistent with previous research in stimulant users. Structural imaging studies of stimulant users have reported decreased volumes in the ACC, vmPFC and amygdala (Franklin et al. 2002; Mackey and Paulus 2013; Makris et al. 2004). Additionally, stimulant use is related to reward based decision-making abnormalities similar to patients with vmPFC lesions (Bechara et al. 2001). No amygdala abnormalities were observed in a study of in-treatment cocaine users in moral compared to neutral dilemma judgments (Verdejo-Garcia et al. 2014). This latter study included 10 cocaine users who were compared to a community control sample, and thus may have been underpowered to reveal group differences in brain responses; criminal cocaine users may also differ from community users (e.g., in severity, comorbidities, or length of use), which could explain discrepant results.

Our participants were chronic stimulant users in a semi-controlled environment. This means their access to drugs, although not non-existent, significantly more limited than in the community. We do not anticipate that the results would be substantively different if our participants were using in the community, given the literature finding that voluntarily abstinent stimulant users still have indications of structural and functional brain abnormalities (Kim et al. 2006; Pace-Schott et al. 2008). Moreover, by investigating stimulant users who were largely abstinent, our results were not confounded by the acute effects of heavy substance use. However, these results may not generalize to individuals actively or inactively using substances at a dependence level; a replication study in active stimulant users is needed to verify the generalizability of our findings to the stimulant using community as a whole. It is also important to note that the results of this study cannot be used to make strong causal claims regarding the influence of stimulant use on moral cognition. It is possible that individuals prone to regular stimulant use exhibited the observed abnormalities in moral processing before they began using stimulants. We did, however, see a change in vmPFC and ACC engagement as a function of increasing duration of stimulant use, a correlation that may indicate the impact of methamphetamine and cocaine use on the brain.

There were some limitations of this study. Many of our participants (both stimulant users and non-stimulant users) had comorbid substance abuse. Our stimulant and non-stimulant groups did differ on levels of non-stimulant substance use; although our results were substantively the same after covarying total years of non-stimulant substance abuse, there may be differences in poly-drug users above and beyond the duration of such use. It is worth noting that comorbid substance use is common in stimulant users (Darke and Hall 1995; Huang et al. 2006). Thus, despite potential complicating effects of poly-drug use, our sample of stimulant users is highly representative of the stimulant using population. Another potential limitation was that our measure of duration did not account for the amount of the drugs used. Although previous research indicates that the duration measure of stimulant use can have meaningful correlates in the brain (i.e., Ersche et al. 2012, 2013; Paulus et al. 2002, Bolla et al. 2003) this may not have adequately quantified severity of use. 
In conclusion, regular stimulant users demonstrated abnormal neural activity during moral processing in fronto-limbic regions. Specifically, lifetime regular stimulant users had hypoactivation in the amygdala, while duration of stimulant use was related to decreased ACC engagement. These results correspond to the fronto-limbic moral processing system, suggesting that stimulant users may have impairment in regions in this system. This is the first study to suggest impairments in the neural systems of moral processing in both cocaine and methamphetamine users. Although further research into the connectivity of systems in stimulant use is needed, this provides promising initial understanding of fronto-limbic deficits in stimulant users.

\section{Acknowledgments}

Research reported in this publication was supported by the National Institute of Mental Health and National Institute on Drug Abuse under R01MH070539, R01DA026964, and R01DA026505 to Kent A. Kiehl. The content is solely the responsibility of the authors and does not necessarily represent the official views of the National Institutes of Health.

\section{References}

Aharoni E, Vincent GM, Harenski CL, Calhoun VD, Sinnott-Armstrong W, Gazzaniga MS, Kiehl KA. Neuroprediction of future rearrest. Proceedings of the National Academy of Sciences. 2013; 110:6223-6228.

Alia-Klein N, Parvaz MA, Woicik PA, Konova AB, Maloney T, Shumay E, Wang RL, Telang F, Biegon A, Wang GJ, Fowler JS, Tomasi D, Volkow ND, Goldstein RZ. Gene x Disease Interaction on Orbitofrontal Gray Matter in Cocaine Addiction. Archives of general psychiatry. 2011; 68:283294. [PubMed: 21383264]

Aron JL, Paulus MP. Location, location: using functional magnetic resonance imaging to pinpoint brain differences relevant to stimulant use. Addiction. 2007; 102:33-43. [PubMed: 17493051]

Banks SJ, Eddy KT, Angstadt M, Nathan PJ, Phan KL. Amygdala-frontal connectivity during emotion regulation. Soc Cogn Affect Neurosci. 2007; 2:303-312. [PubMed: 18985136]

Barbas H, Saha S, Rempel-Clower N, Ghashghaei T. Serial pathways from primate prefrontal cortex to autonomic areas may influence emotional expression. Bmc Neurosci. 2003; 4:25. [PubMed: 14536022]

Bartzokis G, Beckson M, Lu PH, Edwards N, Rapoport R, Wiseman E, Bridge P. Age-related brain volume reductions in amphetamine and cocaine addicts and normal controls: implications for addiction research. Psychiat Res-Neuroim. 2000; 98:93-102.

Bechara A, Damasio AR. The somatic marker hypothesis: A neural theory of economic decision. Games and economic behavior. 2005; 52:336-372.

Bechara A, Dolan S, Denburg N, Hindes A, Anderson SW, Nathan PE. Decision-making deficits, linked to a dysfunctional ventromedial prefrontal cortex, revealed in alcohol and stimulant abusers. Neuropsychologia. 2001; 39:376-389. [PubMed: 11164876]

BJSBoJS. Drug Use and Dependence, State and Federal Prisoners 2004. 2004.

Blair RJR. The amygdala and ventromedial prefrontal cortex in morality and psychopathy. Trends Cogn Sci. 2007; 11:387-392. [PubMed: 17707682]

Bolla K, Eldreth D, London E, Kiehl K, Mouratidis M, Contoreggi C, Matochik J, Kurian V, Cadet J, Kimes A, et al. Orbitofrontal cortex dysfunction in abstinent cocaine abusers performing a decision-making task. Neuroimage. 2003; 19:1085-1094. [PubMed: 12880834]

Brodie JD, Figueroa E, Laska EM, Dewey SL. Safety and efficacy of $\boldsymbol{\gamma}$-vinyl GABA (GVG) for the treatment of methamphetamine and/or cocaine addiction. Synapse. 2005; 55:122-125. [PubMed: 15543630] 
Bzdok D, Schilbach L, Vogeley K, Schneider K, Laird AR, Langner R, Eickhoff SB. Parsing the neural correlates of moral cognition: ALE meta-analysis on morality, theory of mind, and empathy. Brain Structure and Function. 2012; 217:783-796. [PubMed: 22270812]

Caldwell BM, Harenski CL, Harenski KA, Fede SJ, Steele VR, Koenigs MR, Kiehl KA. Abnormal frontostriatal activity in recently abstinent cocaine users during implicit moral processing. Front Hum Neurosci. 2015; 9

Ciaramelli E, Muccioli M, Ladavas E, di Pellegrino G. Selective deficit in personal moral judgment following damage to ventromedial prefrontal cortex. Soc Cogn Affect Neurosci. 2007; 2:84-92. [PubMed: 18985127]

Clark VP, Beatty GK, Anderson RE, Kodituwakku P, Phillips JP, Lane TD, Kiehl KA, Calhoun VD. Reduced fMRI activity predicts relapse in patients recovering from stimulant dependence. Hum Brain Mapp. 2014; 35:414-428. [PubMed: 23015512]

Crunelle CL, Veltman DJ, Booij J, van Emmerik-van Oortmerssen K, van den Brink W. Substrates of neuropsychological functioning in stimulant dependence: a review of functional neuroimaging research. Brain Behav. 2012; 2:499-523. [PubMed: 22950052]

Cunningham WA, Johnson MK, Raye CL, Gatenby JC, Gore JC, Banaji MR. Separable neural components in the processing of black and white faces. Psychol Sci. 2004; 15:806-813. [PubMed: 15563325]

Darke S, Hall W. Levels and correlates of polydrug use among heroin users and regular amphetamine users. Drug and alcohol dependence. 1995; 39:231-235. [PubMed: 8556972]

Daumann J, Koester P, Becker B, Wagner D, Imperati D, Gouzoulis-Mayfrank E, Tittgemeyer M. Medial prefrontal gray matter volume reductions in users of amphetamine-type stimulants revealed by combined tract-based spatial statistics and voxel-based morphometry. Neuroimage. 2011; 54:794-801. [PubMed: 20817105]

Dixon SD, Bejar R. Echoencephalographic findings in neonates assciiated with maternal cocaine and methamphetamine use: Incidence and clinical correlates. The Journal of pediatrics. 1989; 115:770-778. [PubMed: 2681639]

Ersche KD, Barnes A, Jones PS, Morein-Zamir S, Robbins TW, Bullmore ET. Abnormal structure of frontostriatal brain systems is associated with aspects of impulsivity and compulsivity in cocaine dependence. Brain. 2011; 134:2013-2024. [PubMed: 21690575]

Ersche KD, Jones PS, Williams GB, Turton AJ, Robbins TW, Bullmore ET. Abnormal Brain Structure Implicated in Stimulant Drug Addiction. Science. 2012; 335:601-604. [PubMed: 22301321]

Ferrari V, Smeraldi E, Bottero G, Politi E. Addiction and empathy: a preliminary analysis. Neurol Sci. 2014; 35:855-859. [PubMed: 24379106]

First, M.; Spitzer, R.; Williams, J.; Gibbon, M. Structured clinical interview for DSM-IV (SCID), 1997. American Psychiatric Association; Washington, DC: 1997.

Fletcher PC, Happe F, Frith U, Baker SC, Dolan RJ, Frackowiak RSJ, Frith CD. Other Minds in the Brain - a Functional Imaging Study of Theory of Mind in Story Comprehension. Cognition. 1995; 57:109-128. [PubMed: 8556839]

Fox HC, Axelrod SR, Paliwal P, Sleeper J, Sinha R. Difficulties in emotion regulation and impulse control during cocaine abstinence. Drug Alcohol Depen. 2007; 89:298-301.

Fox HC, Bergquist KL, Casey J, Hong KA, Sinha R. Selective Cocaine-Related Difficulties in Emotional Intelligence: Relationship to Stress and Impulse Control. Am J Addiction. 2011; 20:151-160.

Franklin TR, Acton PD, Maldjian JA, Gray JD, Croft JR, Dackis CA, O'Brien CP, Childress AR. Decreased gray matter concentration in the insular, orbitofrontal, cingulate, and temporal cortices of cocaine patients. Biological Psychiatry. 2002; 51:134-142. [PubMed: 11822992]

Freire L, Roche A, Mangin J-F. What is the best similarity measure for motion correction in fMRI time series? Medical Imaging, IEEE Transactions on. 2002; 21:470-484.

Garavan H, Pankiewicz J, Bloom A, Cho J-K, Sperry L, Ross TJ, Salmeron BJ, Risinger R, Kelley D, Stein EA. Cue-induced cocaine craving: neuroanatomical specificity for drug users and drug stimuli. Am J Psychiat. 2000; 157:1789-1798. [PubMed: 11058476]

Greene JD, Nystrom LE, Engell AD, Darley JM, Cohen JD. The neural bases of cognitive conflict and control in moral judgment. Neuron. 2004; 44:389-400. [PubMed: 15473975] 
Hare, RD. Manual for the Hare Psychopathy Checklist-Revised. Multi-Health Systems; Toronto, CA: 2003.

Heatherton TF, Kozlowski LT, Frecker RC, FAGERSTROM KO. The Fagerström test for nicotine dependence: a revision of the Fagerstrom Tolerance Questionnaire. British journal of addiction. 1991; 86:1119-1127. [PubMed: 1932883]

Hemphill JF, Hart SD, Hare DR. Psychopathy and substance use. J Pers Disord. 1994; 8:169-180.

Henry JD, Mazur M, Rendell PG. Social-cognitive difficulties in former users of methamphetamine. Brit J Clin Psychol. 2009; 48:323-327. [PubMed: 19397848]

Hoffman WF, Schwartz DL, Huckans MS, McFarland BH, Meiri G, Stevens AA, Mitchell SH. Cortical activation during delay discounting in abstinent methamphetamine dependent individuals. Psychopharmacology (Berl). 2008; 201:183-193. [PubMed: 18685833]

Hser Y-I, Huang D, Brecht M-L, Li L, Evans E. Contrasting trajectories of heroin, cocaine, and methamphetamine use. Journal of Addictive Diseases. 2008; 27:13-21. [PubMed: 18956525]

Huang B, Dawson DA, Stinson FS, Hasin DS, Ruan W, Saha TD, Smith SM, Goldstein RB, Grant BF. Prevalence, correlates, and comorbidity of nonmedical prescription drug use and drug use disorders in the United States: Results of the National Epidemiologic Survey on Alcohol and Related Conditions. Journal of Clinical Psychiatry. 2006

Johansen-Berg H, Gutman D, Behrens T, Matthews P, Rushworth M, Katz E, Lozano A, Mayberg H. Anatomical connectivity of the subgenual cingulate region targeted with deep brain stimulation for treatment-resistant depression. Cereb Cortex. 2008; 18:1374-1383. [PubMed: 17928332]

Johnson MK, Raye CL, Mitchell KJ, Touryan SR, Greene EJ, Nolen-Hoeksema S. Dissociating medial frontal and posterior cingulate activity during self-reflection. Soc Cogn Affect Neurosci. 2006; 1:56-64. [PubMed: 18574518]

Johnstone T, van Reekum CM, Urry HL, Kalin NH, Davidson RJ. Failure to regulate: counterproductive recruitment of top-down prefrontal-subcortical circuitry in major depression. The Journal of neuroscience. 2007; 27:8877-8884. [PubMed: 17699669]

Kemmis L, Hall JK, Kingston R, Morgan MJ. Impaired fear recognition in regular recreational cocaine users. Psychopharmacology. 2007; 194:151-159. [PubMed: 17554526]

Kiehl KA, Bates AT, Laurens KR, Hare RD, Liddle PF. Brain potentials implicate temporal lobe abnormalities in criminal psychopaths. J Abnorm Psychol. 2006; 115:443. [PubMed: 16866585]

Kim MJ, Loucks RA, Palmer AL, Brown AC, Solomon KM, Marchante AN, Whalen PJ. The structural and functional connectivity of the amygdala: from normal emotion to pathological anxiety. Behav Brain Res. 2011; 223:403-410. [PubMed: 21536077]

Kim SJ, Lyoo IK, Hwang J, Chung A, Hoon Sung Y, Kim J, Kwon D-H, Chang KH, Renshaw PF. Prefrontal grey-matter changes in short-term and long-term abstinent methamphetamine abusers. The International Journal of Neuropsychopharmacology. 2006; 9:221-228. [PubMed: 15982446]

Kim YT, Kwon DH, Chang YM. Impairments of facial emotion recognition and theory of mind in methamphetamine abusers. Psychiat Res. 2011a; 186:80-84.

Kim YT, Lee JJ, Song HJ, Kim JH, Kwon DH, Kim MN, Yoo DS, Lee HJ, Kim HJ, Chang Y. Alterations in cortical activity of male methamphetamine abusers performing an empathy task: fMRI study. Hum Psychopharm Clin. 2010; 25:63-70.

Koenigs M, Young L, Adolphs R, Tranel D, Cushman F, Hauser M, Damasio A. Damage to the prefrontal cortex increases utilitarian moral judgements. Nature. 2007; 446:908-911. [PubMed: 17377536]

Kohno M, Morales AM, Ghahremani DG, Hellemann G, London ED. Risky decision making, prefrontal cortex, and mesocorticolimbic functional connectivity in methamphetamine dependence. JAMA psychiatry. 2014; 71:812-820. [PubMed: 24850532]

Kohno M, Okita K, Morales A, Robertson C, Dean A, Ghahremani D, Sabb F, Rawson R, Mandelkern M, Bilder R. Midbrain functional connectivity and ventral striatal dopamine D2-type receptors: link to impulsivity in methamphetamine users. Mol Psychiatry. 2016

Koob GF. The role of the striatopallidal and extended amygdala systems in drug addiction. Annals of the New York Academy of Sciences. 1999; 877:445-460. [PubMed: 10415664]

London ED, Kohno M, Morales AM, Ballard ME. Chronic methamphetamine abuse and corticostriatal deficits revealed by neuroimaging. Brain Res. 2015; 1628:174-185. [PubMed: 25451127] 
Mackey S, Paulus M. Are there volumetric brain differences associated with the use of cocaine and amphetamine-type stimulants? Neuroscience \& Biobehavioral Reviews. 2013; 37:300-316. [PubMed: 23253945]

Makris N, Gasic GP, Seidman LJ, Goldstein JM, Gastfriend DR, Elman I, Albaugh MD, Hodge SM, Ziegler DA, Sheahan FS, Caviness VS, Tsuang MT, Kennedy DN, Hyman SE, Rosen BR, Breiter HC. Decreased absolute amygdala volume in cocaine addicts. Neuron. 2004; 44:729-740. [PubMed: 15541319]

Maldjian JA, Laurienti PJ, Burdette JH. Precentral gyrus discrepancy in electronic versions of the Talairach atlas. Neuroimage. 2004; 21:450-455. [PubMed: 14741682]

Maldjian JA, Laurienti PJ, Kraft RA, Burdette JH. An automated method for neuroanatomic and cytoarchitectonic atlas-based interrogation of fMRI data sets. Neuroimage. 2003; 19:1233-1239. [PubMed: 12880848]

Matochik JA, London ED, Eldreth DA, Cadet J-L, Bolla KI. Frontal cortical tissue composition in abstinent cocaine abusers: a magnetic resonance imaging study. Neuroimage. 2003; 19:1095-1102. [PubMed: 12880835]

Mazaika PK, Hoeft F, Glover G, Reiss AL. Methods and software for fMRI analysis of clinical subjects. Neuroimage. 2009; 47:S58.

McLellan AT, Kushner H, Metzger D, Peters R, Smith I, Grissom G, Pettinati H, Argeriou M. The fifth edition of the Addiction Severity Index. J Subst Abuse Treat. 1992; 9:199-213. [PubMed: 1334156]

Miller GA, Chapman JP. Misunderstanding analysis of covariance. J Abnorm Psychol. 2001; 110:40. [PubMed: 11261398]

Moll J, Zahn R, de Oliveira-Souza R, Krueger F, Grafman J. The neural basis of human moral cognition. Nature Reviews Neuroscience. 2005; 6:799-809. [PubMed: 16276356]

Monterosso JR, Ainslie G, Xu J, Cordova X, Domier CP, London ED. Frontoparietal cortical activity of methamphetamine-dependent and comparison subjects performing a delay discounting task. Hum Brain Mapp. 2007; 28:383-393. [PubMed: 16944492]

Morales AM, Lee B, Hellemann G, O’Neill J, London ED. Gray-matter volume in methamphetamine dependence: cigarette smoking and changes with abstinence from methamphetamine. Drug and alcohol dependence. 2012; 125:230-238. [PubMed: 22445480]

Moreno-Lopez L, Catena A, Fernandez-Serrano MJ, Delgado-Rico E, Stamatakis EA, Perez-Garcia M, Verdejo-Garcia A. Trait impulsivity and prefrontal gray matter reductions in cocaine dependent individuals. Drug Alcohol Depen. 2012; 125:208-214.

Moretto G, Ladavas E, Mattioli F, di Pellegrino G. A psychophysiological investigation of moral judgment after ventromedial prefrontal damage. J Cogn Neurosci. 2010; 22:1888-1899. [PubMed: 19925181]

Morgan MJ, Marshall JP. Deficient fear recognition in regular cocaine users is not attributable to elevated impulsivity or conduct disorder prior to cocaine use. J Psychopharmacol. 2013; 27:526532. [PubMed: 23438501]

Motzkin JC, Philippi CL, Wolf RC, Baskaya MK, Koenigs M. Ventromedial prefrontal cortex is critical for the regulation of amygdala activity in humans. Biol Psychiat. 2015; 77:276-284. [PubMed: 24673881]

Nakama H, Chang LD, Fein G, Shimotsu R, Jiang CS, Ernst T. Methamphetamine users show greater than normal age-related cortical gray matter loss. Addiction. 2011; 106:1474-1483. [PubMed: 21438934]

NIDA NIoDA. Trends \& Statistics. 2014

Pace-Schott EF, Morgan PT, Malison RT, Hart CL, Edgar C, Walker M, Stickgold R. Cocaine users differ from normals on cognitive tasks which show poorer performance during drug abstinence. Am J Drug Alcohol Abuse. 2008; 34:109-121. [PubMed: 18161649]

Paulus MP, Hozack NE, Zauscher BE, Frank L, Brown GG, Braff DL, Schuckit MA. Behavioral and functional neuroimaging evidence for prefrontal dysfunction in methamphetamine-dependent subjects. Neuropsychopharmacol. 2002; 26:53-63.

Payer DE, Lieberman MD, London ED. Neural correlates of affect processing and aggression in methamphetamine dependence. Arch Gen Psychiatry. 2011; 68:271-282. [PubMed: 21041607] 
Payer DE, Lieberman MD, Monterosso JR, Xu J, Fong TW, London ED. Differences in cortical activity between methamphetamine-dependent and healthy individuals performing a facial affect matching task. Drug and alcohol dependence. 2008; 93:93-102. [PubMed: 17964741]

Peters RH, Greenbaum PE, Edens JF, Carter CR, Ortiz MM. Prevalence of DSM-IV substance abuse and dependence disorders among prison inmates. Am J Drug Alcohol Abuse. 1998; 24:573-587. [PubMed: 9849769]

Preller KH, Hulka LM, Vonmoos M, Jenni D, Baumgartner MR, Seifritz E, Dziobek I, Quednow BB. Impaired emotional empathy and related social network deficits in cocaine users. Addict Biol. 2014; 19:452-466. [PubMed: 23800218]

Psychological Software Tools. E-Prime. Psychological Software Tools; Pittsburgh, PA: 2012.

Rando K, Tuit K, Hannestad J, Guarnaccia J, Sinha R. Sex differences in decreased limbic and cortical grey matter volume in cocaine dependence: a voxel-based morphometric study. Addict Biol. 2013; 18:147-160. [PubMed: 23167305]

Rawson R, Huber A, Brethen P, Obert J, Gulati V, Shoptaw S, Ling W. Methamphetamine and cocaine users: differences in characteristics and treatment retention. Journal of Psychoactive Drugs. 2000; 32:233-238. [PubMed: 10908013]

Roy AK, Shehzad Z, Margulies DS, Kelly AC, Uddin LQ, Gotimer K, Biswal BB, Castellanos FX, Milham MP. Functional connectivity of the human amygdala using resting state fMRI. Neuroimage. 2009; 45:614-626. [PubMed: 19110061]

Ryan JJ, Lopez SJ, Werth TR. Development and preliminary validation of a Satz-Mogel short form of the WAIS-III in a sample of persons with substance abuse disorders. Int J Neurosci. 1999; 98:131140. [PubMed: 10395365]

SAMSHA SAaMHSA. Results from the 2010 National Survey on Drug Use and Health: Summary of National Findings. Substance Abuse and Mental Health Services Administration SAMHSA; Rockville, MD: 2011. NSDUH Series H-41

SAMSHA SAaMHSA. Results from the 2013 National Survey on Drug Use and Health: Summary of National Findings. Substance Abuse and Mental Health Services Administration; Rockville, MD: 2014.

Schaich Borg J, Sinnott-Armstrong W, Calhoun VD, Kiehl KA. Neural basis of moral verdict and moral deliberation. Soc Neurosci. 2011; 6:398-413. [PubMed: 21590588]

Shackman AJ, Salomons TV, Slagter HA, Fox AS, Winter JJ, Davidson RJ. The integration of negative affect, pain and cognitive control in the cingulate cortex. Nature Reviews Neuroscience. 2011; 12:154-167. [PubMed: 21331082]

Sim ME, Lyoo IK, Streeter CC, Covell J, Sarid-Segal O, Ciraulo DA, Kim MJ, Kaufman MJ, Yurgelun-Todd DA, Renshaw PF. Cerebellar gray matter volume correlates with duration of cocaine use in cocaine-dependent subjects. Neuropsychopharmacol. 2007; 32:2229-2237.

Thomas BC, Croft KE, Tranel D. Harming kin to save strangers: further evidence for abnormally utilitarian moral judgments after ventromedial prefrontal damage. J Cogn Neurosci. 2011; 23:2186-2196. [PubMed: 20946057]

Thompson PM, Hayashi KM, Simon SL, Geaga JA, Hong MS, Sui YH, Lee JY, Toga AW, Ling W, London ED. Structural abnormalities in the brains of human subjects who use methamphetamine. J Neurosci. 2004; 24:6028-6036. [PubMed: 15229250]

Urry HL, Van Reekum CM, Johnstone T, Kalin NH, Thurow ME, Schaefer HS, Jackson CA, Frye CJ, Greischar LL, Alexander AL. Amygdala and ventromedial prefrontal cortex are inversely coupled during regulation of negative affect and predict the diurnal pattern of cortisol secretion among older adults. The Journal of Neuroscience. 2006; 26:4415-4425. [PubMed: 16624961]

van der Plas EA, Crone EA, van den Wildenberg WP, Tranel D, Bechara A. Executive control deficits in substance-dependent individuals: a comparison of alcohol, cocaine, and methamphetamine and of men and women. Journal of clinical and experimental neuropsychology. 2009; 31:706-719. [PubMed: 19037812]

Verdejo-Garcia A, Contreras-Rodríguez O, Fonseca F, Cuenca A, Soriano-Mas C, Rodriguez J, PardoLozano R, Blanco-Hinojo L, de Sola Llopis S, Farré M, Torrens M, Pujol J, de la Torre R. Functional alteration in frontolimbic systems relevant to moral judgment in cocaine-dependent subjects. Addiction Biology. 2014; 19:272-281. [PubMed: 22784032] 
Vogt BA, Finch DM, Olson CR. Functional heterogeneity in cingulate cortex: the anterior executive and posterior evaluative regions. Cereb Cortex. 1992; 2:435-443. [PubMed: 1477524]

Walsh Z, Allen LC, Kosson DS. Beyond social deviance: Substance use disorders and the dimensions of psychopathy. J Pers Disord. 2007; 21:273-288. [PubMed: 17536940]

Wechsler, D. WAIS-III: Administration and scoring manual: Wechsler adult intelligence scale. Psychological Corporation; 1997.

Williams LM, Das P, Liddell BJ, Kemp AH, Rennie CJ, Gordon E. Mode of functional connectivity in amygdala pathways dissociates level of awareness for signals of fear. The Journal of neuroscience. 2006; 26:9264-9271. [PubMed: 16957082] 

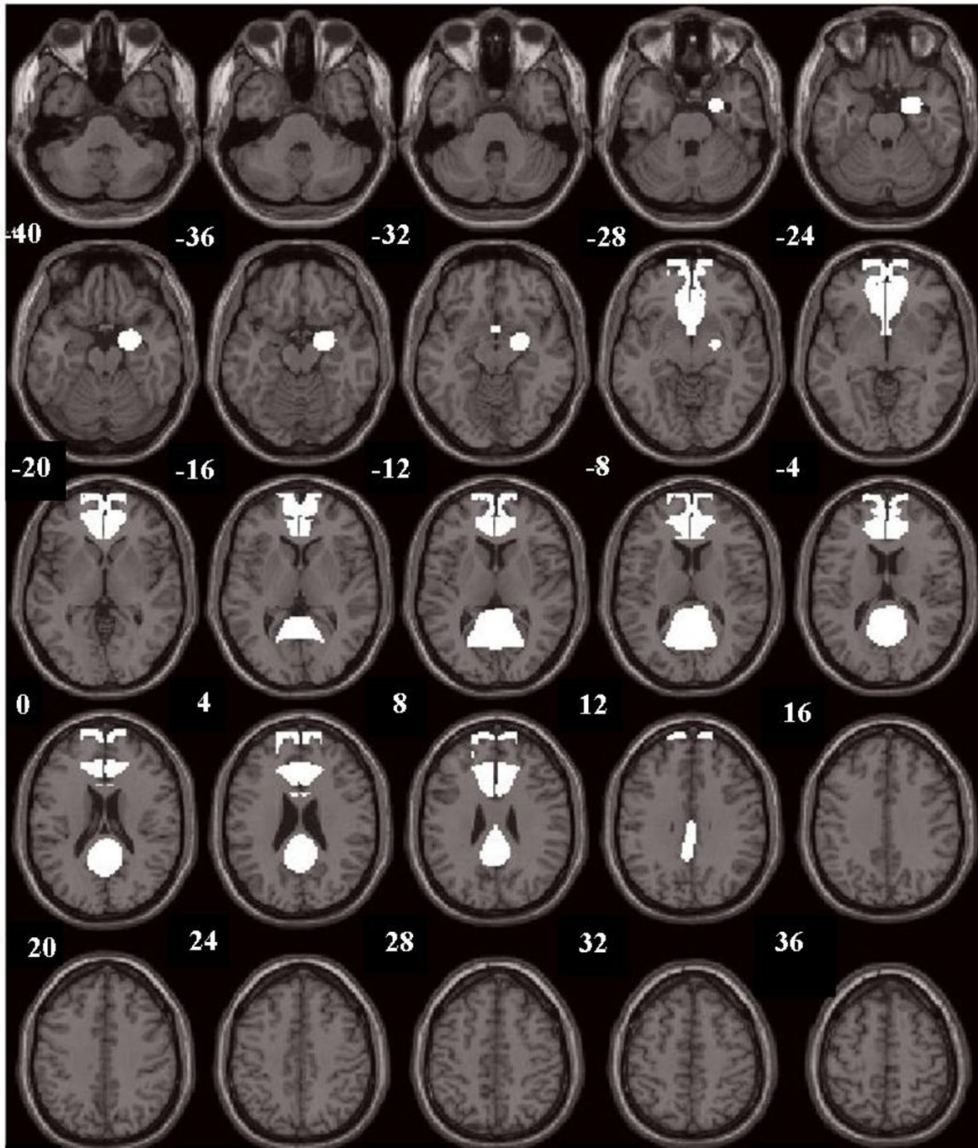

40

44

48

52

56
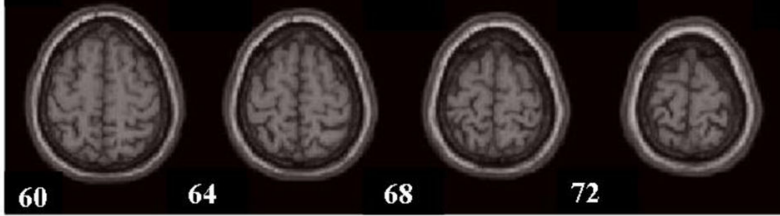

Fig 1.

Regions of interests for the analyses looking at stimulant use analyses are represented using actual masks plotted as blobs on a canonical T1 template. 


\section{Table 1}

Characteristics of Lifetime Stimulant and Non-Stimulant Users Correlations Between Covariates in Lifetime Regular Stimulant Users

\begin{tabular}{lcccc}
\hline Covariate & \multicolumn{2}{c}{ Non-Regular Stimulant Users } & \multicolumn{2}{c}{ Lifetime Regular Stimulant Users } \\
\hline & Mean & SD & Mean & SD \\
\hline Age & 36.11 & 10.79 & 33.85 & 9.97 \\
IQ & 97.25 & 11.24 & 98.52 & 12.57 \\
Years Regular Stim Use* & 0.00 & 0.00 & 8.75 & 9.62 \\
Years Regular Non-Stim Use* & 11.88 & 11.59 & 23.91 & 14.47 \\
PCL-R Total Score & 20.80 & 7.75 & 22.01 & 6.95 \\
Fagerstrom Symptoms & 3.51 & 2.94 & 3.25 & 3.06 \\
Age of First Cocaine Use & - & - & 19.01 & 5.839 \\
Age of First Meth Use & - & - & 20.80 & 6.804 \\
\hline
\end{tabular}

Note: Asterisks in covariate column indicates significant between-group difference according to an independent samples $t$-test at a level of $p<.001$ 


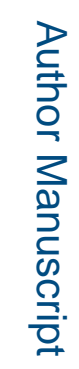

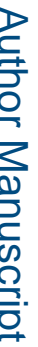

로을

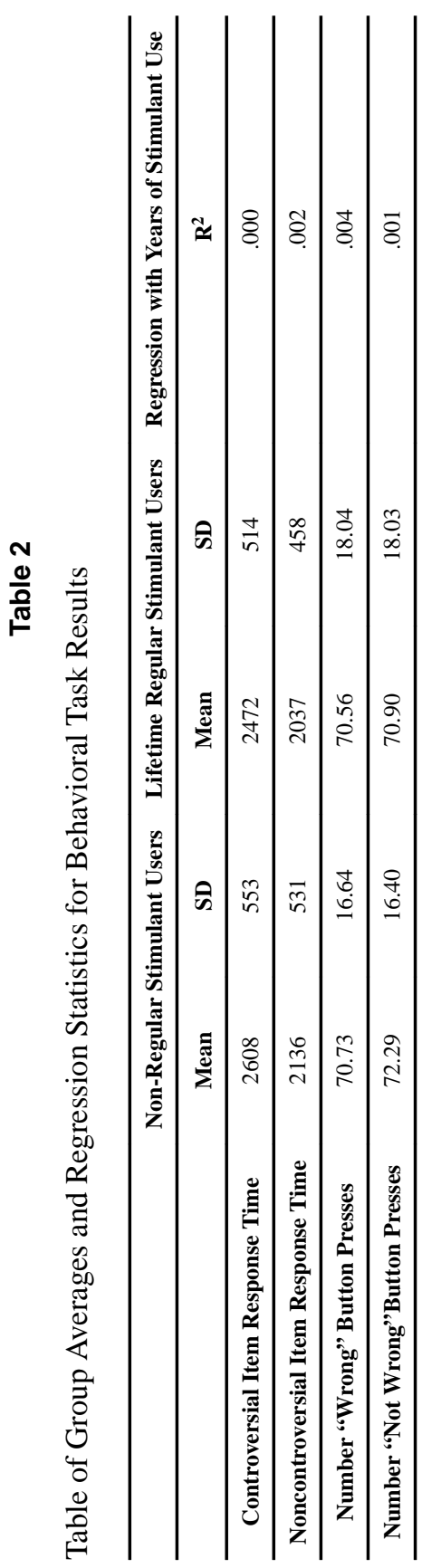

要

Psychopharmacology (Berl). Author manuscript; available in PMC 2017 September 01 
Fede et al.

Page 19

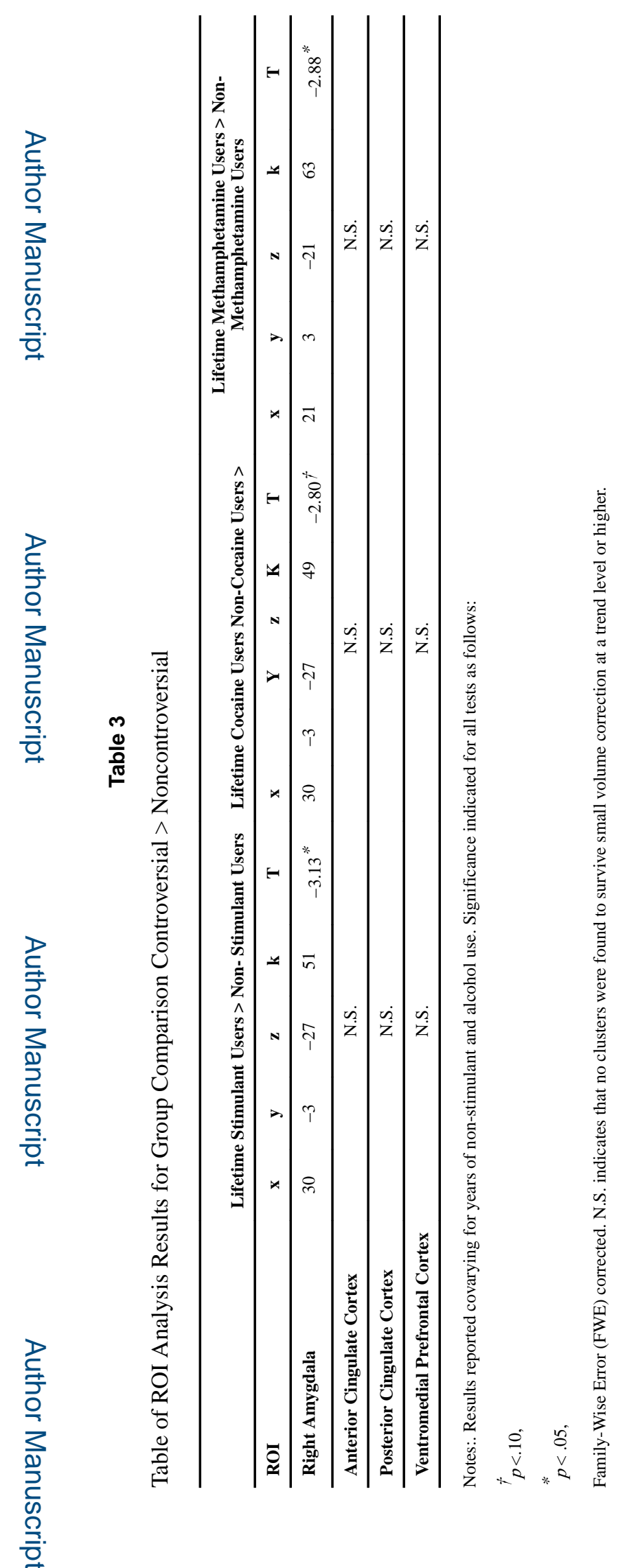

Psychopharmacology (Berl). Author manuscript; available in PMC 2017 September 01. 

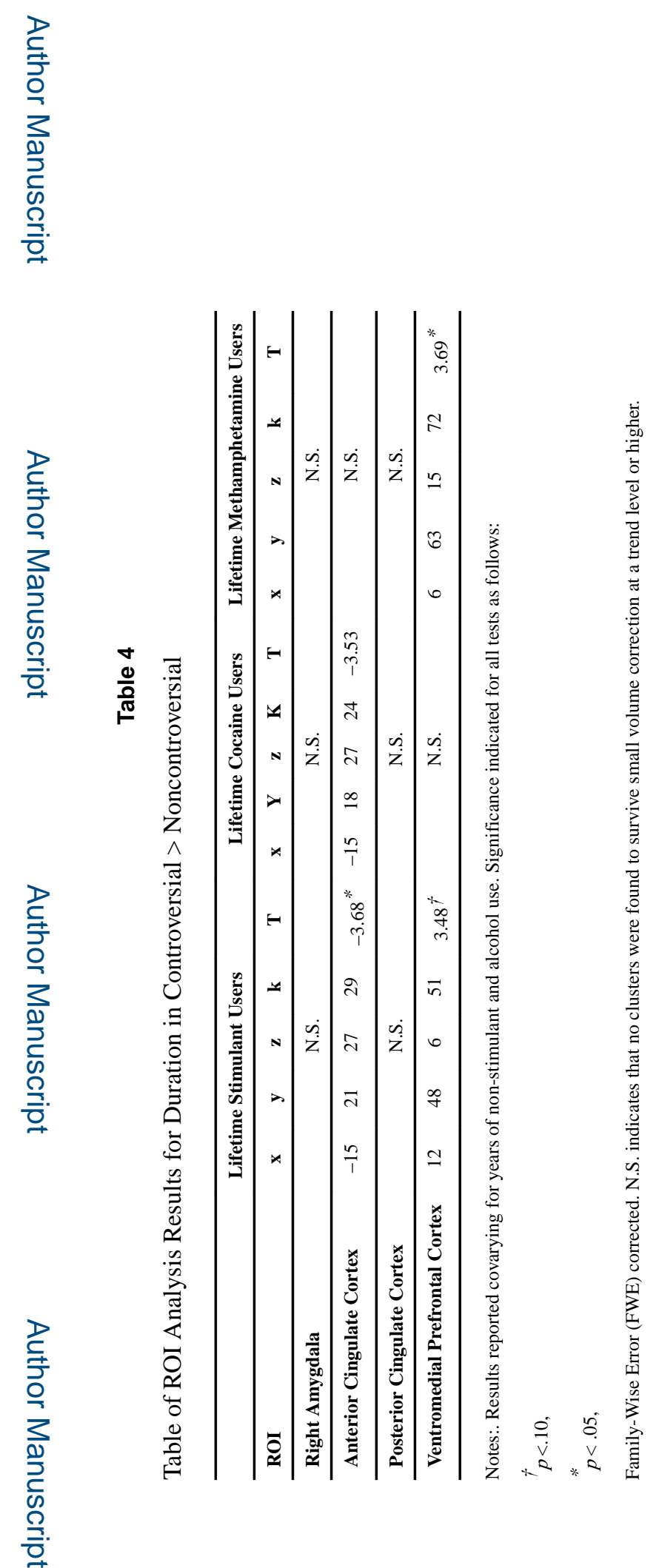

Psychopharmacology (BerI). Author manuscript; available in PMC 2017 September 01. 